\title{
Interactive comment on "Precise timing of MIS 7 sub-stages from the Austrian Alps" by Kathleen A. Wendt et al.
}

\section{Anonymous Referee \#1}

Received and published: 3 December 2020

\section{General comment}

This manuscript offers data of great interest to our community since it provides - with excellent precision - the timing of TIII and different substages of MIS7 interval. This time interval is not well represented in terrestrial records all over the world and from marine records obtaining an independent chronology is not easy for that period. Then, the novelty and interest of this study are assured. The data come from three different speleothems from the same cave, Spannagel Cave in Central Alps; two of the stalagmites are new ones (SPA146 \& 183) and cover MIS7/6 transition and the other one (SPA-21) has been certainly improved in its chronology (previous age model in Spötl et al., 2008) and covers MIS7 in its totallity. As a general comment, I consider this manuscript suitable to be published in CP with some moderate changes. I suggest, 
focusing on the SPA-21 stalagmite and MIS7 chronology and excluding the other two speleothems (if not excluded, at least modulate the sentences regarding replicationsee below).

\section{Specific comments}

1.- Replication of the three stalagmites. I am not very convinced of the data presented from the two new stalagmites. .. and I think the authors should consider the benefits of including them here. Amplifying Fig. 3, I am not completely sure if both new stalagmites show the rapid change in d180 at 192-191 ka, as SPA-21 does (I don't think so, but it is difficult to evaluate in the figure). On the other hand, $\mathrm{d} 13 \mathrm{C}$ values are certainly not replicated. Therefore, taking into account that the SPA-21 signal is not replicated by SPA146 and SPA183 records, since those two stalagmites start once SPA-21 stops growing (Fig. 3), I would suggest the authors to consider the advantage of including them in the study. Additionally, SPA146 and SPA183 present some issues close to the base of their MIS7 section (see Fig. S2) and I am afraid that those problems related to diagenetic alteration may still influence above that section. My comment is also based on the high correlation among $\mathrm{d} 18 \mathrm{O}$ and $\mathrm{d} 13 \mathrm{C}$ in the provided Hendy tests (Fig. S3) that is not present in SPA-21 (Spotl et al., 2008) thus suggesting kinetic effects. In addition, the age model of these two stalagmites from 197.1 to $191.4( \pm 0.3)$ ka is not present in the manuscript. . . that is certainly important to consider those stalagmites here.

In any case, if the authors still maintain SPA146 and SPA83 data in the paper, they have to provide their age models and avoid statements such as that one from line 165 ("....final shift towards lower $\delta 180$ values from 197.1 to $191.4( \pm 0.3)$ ka and coincides with the MIS 7/6 transition, the latter portion of which is replicated by stalagmites SPA 146 and 183") since I don't see any portion replicated. Or line 140 ("Hendy tests on the new stalagmites SPA146 (averaged R2=0.88) and SPA183 (averaged R2=0.84) indicate possible kinetic influences (see Fig. S3), although the replication in the general trend and absolute values of all three stalagmites argue against significant kinetic ef-

Printer-friendly version

Discussion paper

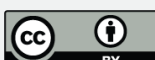


fects") since there is not a replication in the general trend or absolute values in the three stalagmites.

2.- Source of precipitation. The authors indicate two main sources of precipitation in this region, which can be differentiated by the d180 isotopic values. I agree with this statement, but I consider that Atlantic sourced precipitation may not be much more negative than the Mediterranean one, depending on the moisture uptake along the longer pathway. Rainout effect is sometimes compensated by the more positive recycled moisture that is being incorporated in the way from the source to the Central Alps. It is then important to take into account the moisture recharge through the long pathway as, sometimes, the result is an enrichment derived by the effect of enriched inland moisture compared to ocean moisture. See, for example, Chakraborty et al., (2016) and Krklec and Domínguez-Villar (2014). More references on this topic or an additional study of moisture sources in the Central Alps may be of interest to clearly ascribe the Atlantic source with more negative d180 values.

3. Similarity with $\mathrm{d} 180$ monsoon records. The authors indicate several times in the discussion the high similarity with Asian monsoon records (lines 175, lines 235, etc); I think these statements should be modulated as I observe many differences in timing and pattern in Fig. 4. Both the similarities and the differences must be clearly described. For example, the time of TIlla is completely different, also the pattern. The time of 7d as defined in Spanagel (234-216 ka) does not coincide at all with Chinese monsoon timing. Please indicate and explain potential mechanisms for those differences.

\section{Minor comments}

- Line 26. I miss one or two references here to support this statement.

- Line 140. Replication just happens during very short periods of time, if any, and the values and trends are not so well reproduced. I would not use those criteria for discarding kinetic effects.

Interactive 
- Line 147. This just applies for SPA21, the other two stalagmites display more negative values. Please, explain why.

CPD

- Figure 4. I would suggest adding to this figure the duration of MIS7 substages (lines or shaded squares) to really see when they start and finish, not only the "peak" indicated by the name in Fig. 4D.

- Figure S3. I think these data correspond to two different lamina in every stalagmite. Please indicate it in the graph or caption.

\section{References}

Chakraborty, S., Sinha, N., Chattopadhyay, R., Sengupta, S., Mohan, P. M. and Datye, A.: Atmospheric controls on the precipitation isotopes over the Andaman Islands, Bay of Bengal, Scientific Reports, 6(1), doi:10.1038/srep19555, 2016.

Krklec, K. and Domínguez-Villar, D.: Quantification of the impact of moisture source regions on the oxygen isotope composition of precipitation over Eagle Cave, central Spain, Geochimica et Cosmochimica Acta, doi:10.1016/j.gca.2014.03.011, 2014.

Spötl, C., Scholz, D. and Mangini, A.: A terrestrial U/Th-dated stable isotope record of the Penultimate Interglacial, Earth and Planetary Science Letters, 276(3-4), 283-292, doi:10.1016/j.epsl.2008.09.029, 2008.

Interactive comment on Clim. Past Discuss., https://doi.org/10.5194/cp-2020-145, 2020. 